\title{
Leer, comprender, argumentar: el comentario de texło como recurso didáctico fundamental
}

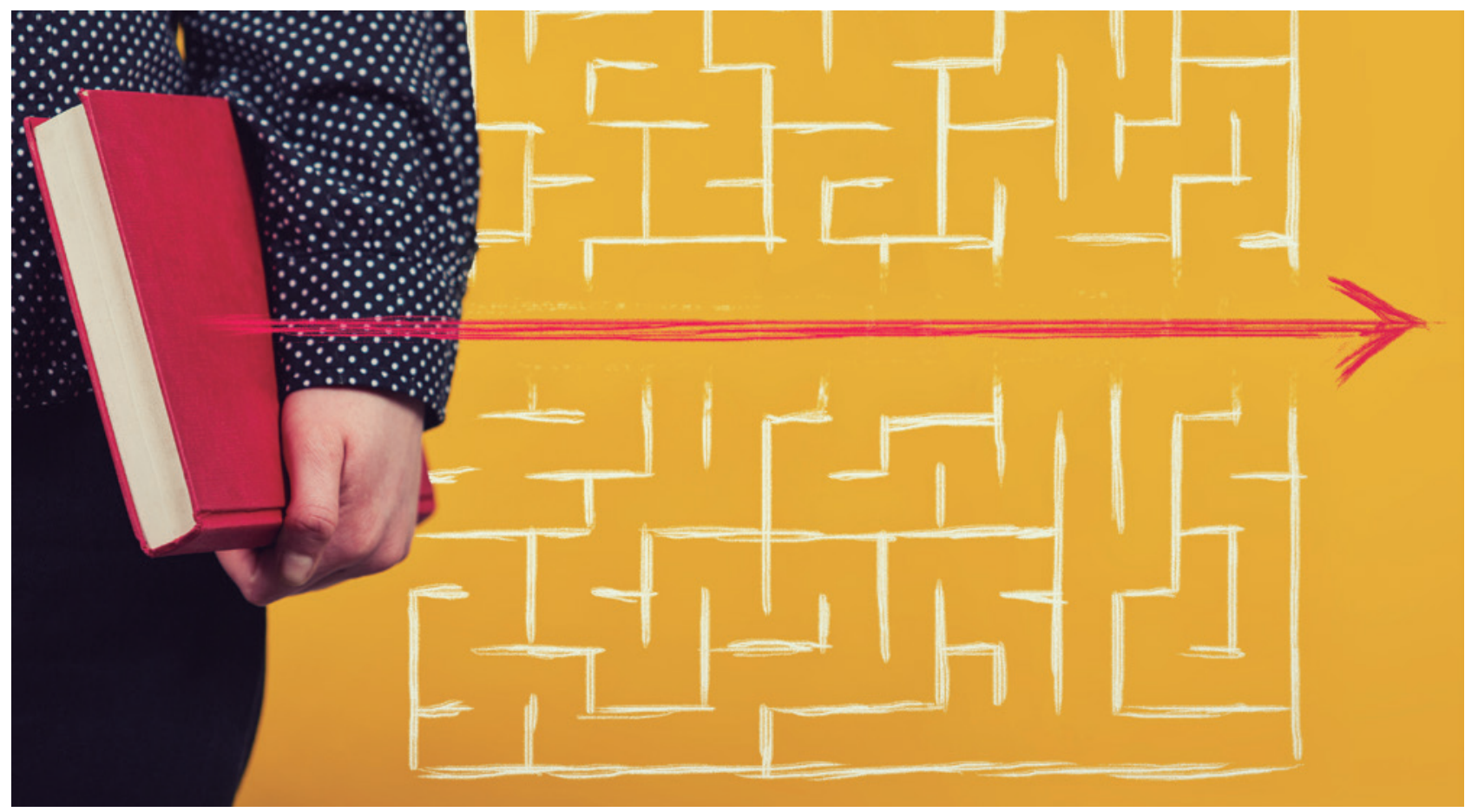

Ante el deterioro de competencias fundamentales para el aprendizaje como la comprensión lectora y la formación del pensamiento crítico, el comentario de texto deviene una herramienta didáctica

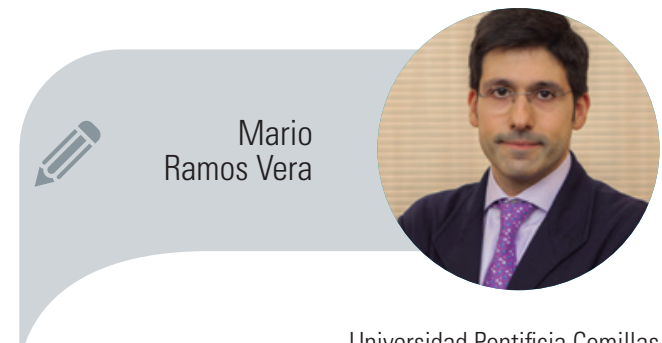

Universidad Pontificia Comillas mrvera@comillas.edu fundamental. Se trata de una lectura crítica y analítica que invita a la iniciación al conocimiento, al proceso reflexivo y a la especulación abstracta por medio de herramientas metodológicas que, en el caso de las Ciencias Sociales (y Humanas) se erigen fundamentales para ayudar a cimentar una capacidad crítica fundamental para el alumno. 


\section{Introducción}

En el momento de escribir estas líneas resulta posible atisbar la entrada en vigor del proyecto de ley de Educación que aprobó el Gobierno en febrero de 2019, una vez resulte sustanciado el proceso de tramitación parlamentaria. Esta Ley Orgánica de Modificación de la LOE (LOMLOE), pese a las novedades incluidas, mantiene vigente entre sus objetivos la estructura de competencias que el alumno debería obtener en cada etapa educativa, estructura ya establecida por normas anteriores como la LOGSE o la LOE. Así, la LOGSE, en sus artículos 19 y 26 -y la LOE en sus artículos 23 y 33-, establece respectivamente que el alumno de ESO y Bachillerato debería ser capaz de comprender textos y mensajes complejos, utilizar con sentido crítico fuentes de información en relación con las realidades contemporáneas y adquirir conocimientos nuevos gracias a su propio esfuerzo.

La relevancia objetiva de la comprensión lectora para la política educativa es evidente. En virtud de la centralidad de esta capacidad, en pleno auge educativo de metodologías como el aprendizaje basado en problemas o el aprendizaje cooperativo, me gustaría plantear la necesidad de recuperar el comentario de texto como una herramienta didáctica fundamental. De esta manera, sería posible potenciar la capacidad de lectura y la formación del pensamiento crítico. Más allá de la caricatura del comentario de texto que concibe esta propuesta como una actividad árida, propia de tiempos pasados y escasamente útil —excepto en disciplinas académicas como la Filosofía o la Historia-, considero necesario defender su valor didáctico. No en vano, el comentario de texto incide sobre la lectura crítica y analítica, sobre el proceso de iniciación al conocimiento y sobre la especulación abstracta en ámbitos tan cercanos como las Ciencias Sociales y Humanas. Con esta intención voy a plantear el siguiente itinerario: (1) el objeto y las características del comentario de texto, esto es, ¿por qué resulta relevante hoy en día?; (2) su aplicación didáctica y sus especificidades, aquello que lo hace

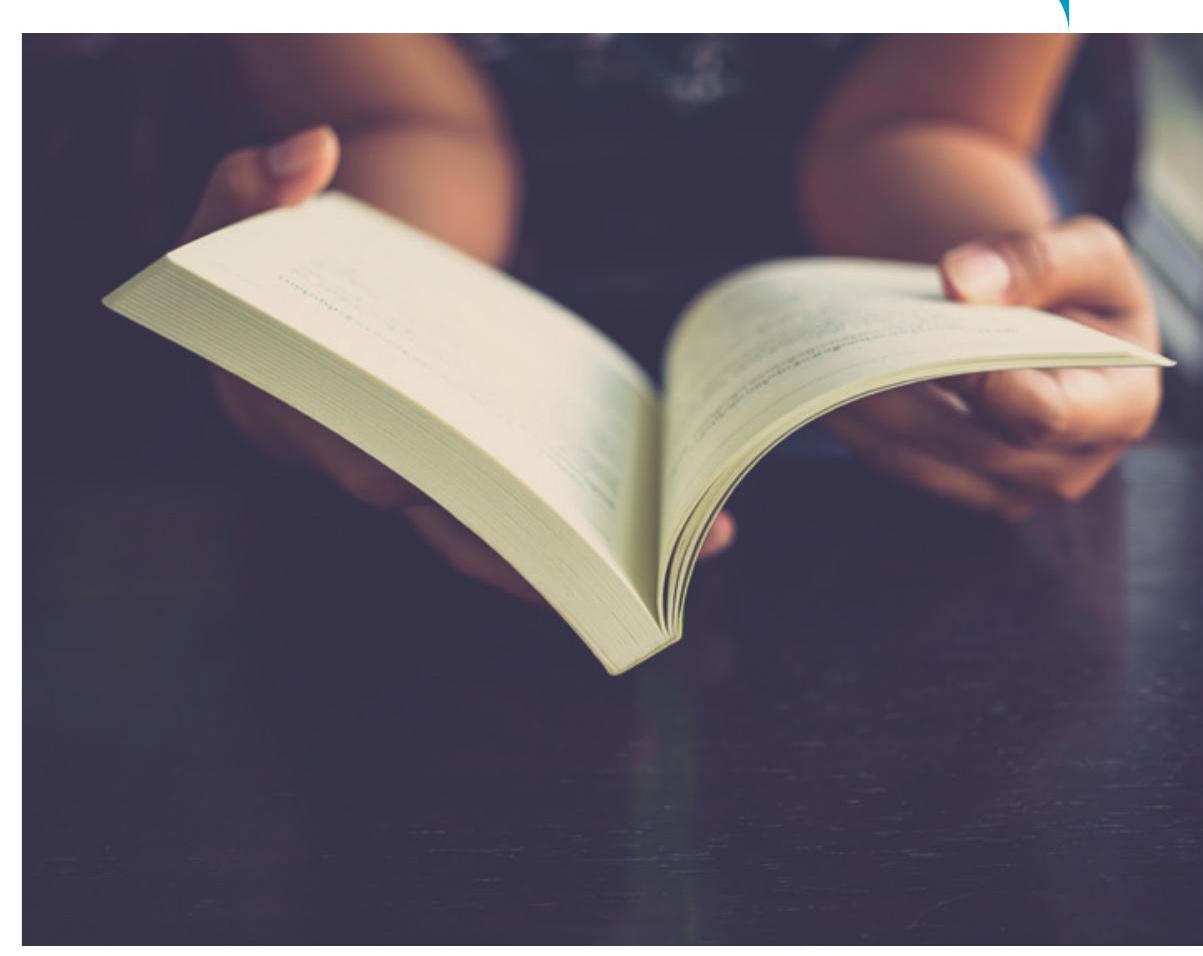

especialmente significativo en el proceso de aprendizaje; (3) la aplicación práctica del mismo; y, por último (4), unas reflexiones finales que sintetizan lo expuesto en este artículo.

\section{El comentario de texto y las \\ Ciencias Sociales (y Humanas)}

Las transformaciones sociales, económicas y políticas han generado profundos cambios. Así, desde la posmodernidad líquida de Bauman hasta la aceleración del tiempo social de Hartmut Rosa, vivimos un tiempo de dinamismo e incertidumbre del que no escapa la educación. La primacía de estudios de carácter técnicopráctico - tanto en las ciencias aplicadas como en las ciencias sociales empíricas - responden a las exigencias de un mercado laboral centrado en las profesiones productivas. Consecuencia necesaria es el creciente pragmatismo, utilitarismo y cientificismo de los planes educativos. El desenlace resulta conocido: la consabida erosión de las disciplinas conocidas tradicionalmente como Humanidades. No tan evidente, pero igualmente cierto, es el peaje que han pagado las Ciencias Sociales, puesto que la atención por garantizar su relevancia práctica corre el riesgo de condenar a la penuria teórica dicha rama del conocimiento.

El comentario de texto consta de varios objetivos transversales e interdisci- 


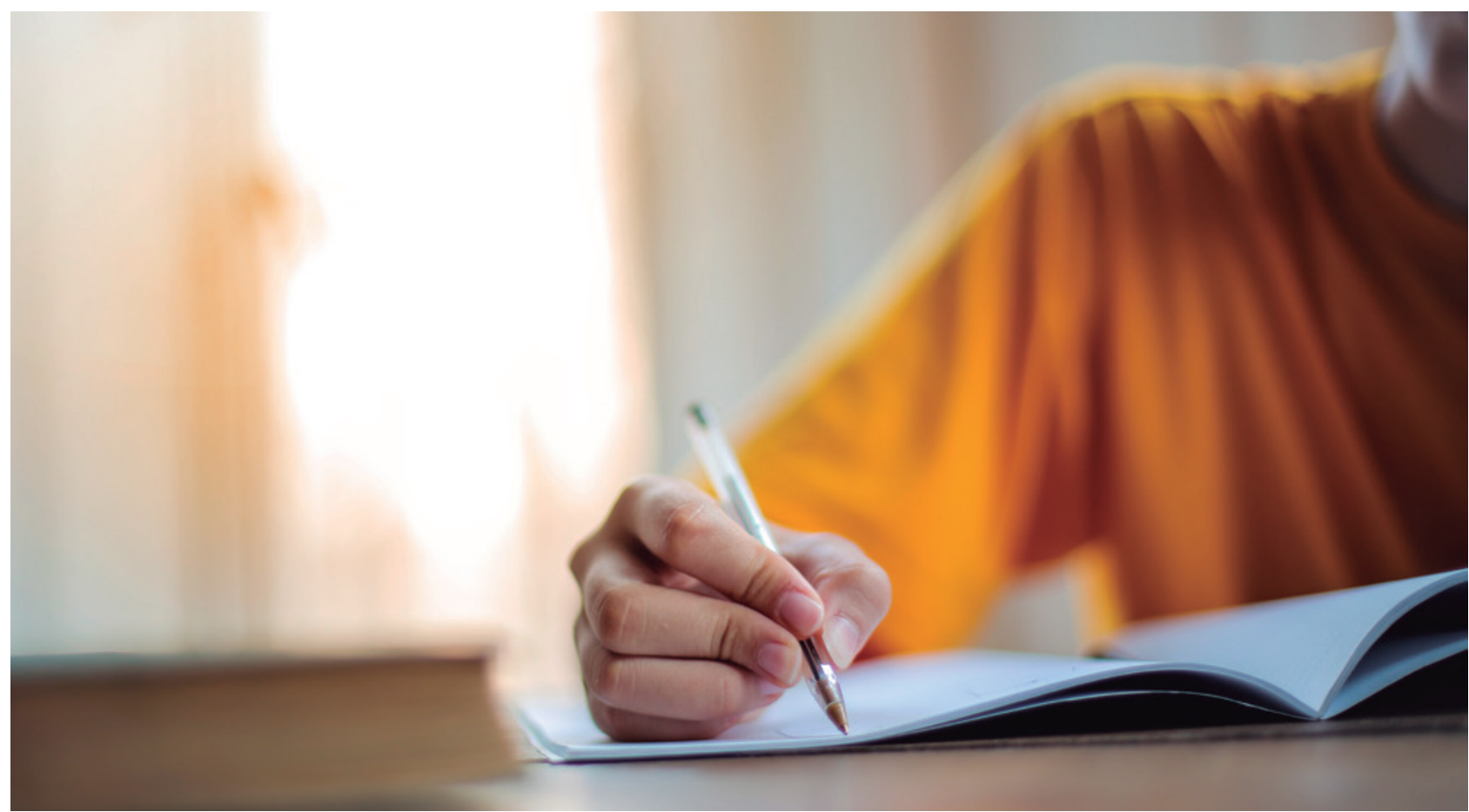

\section{En un momento en el que se ponderan sin parangón las nuevas metodologías, realizar una apología del comentario del texto no supone una revolución pedagógica. Por el contrario, equivale a restaurar la rradición pedagógica -acaso una de sus mejores partes-}

plinarios que vinculan a todas las Ciencias Sociales y Humanas. Tanto si el comentario obedece a la Literatura, la Geografía o a la Historia, dichas disciplinas tienden - desde enfoques metodológicos particulares - a formular preguntas sobre la sociedad, la condición humana y su relación con el entorno. Comentar un texto es una invitación a protagonizar las aventuras previas de la historia y la cultura, a interrogarse sobre el fundamento de las sociedades. En este sentido, resulta relevante para los estudiantes de Ciencias Sociales y Humanas, pues permite forjar mapas de argumentos y conclusiones susceptibles de evaluación y revisión. Cada materia concreta - Historia, Economía, Lengua...- debe garantizar el estatuto epistemológico del comentario de texto, su metodología y su sesgo cognitivo concretos. En última instancia, el profesor debe establecer lo que se debe y se quie- re enseñar en virtud del texto en función de los objetivos de aprendizaje. Por ello, el texto seleccionado debe plantear unas metas realistas para alcanzar los siguientes objetivos: (1) adquirir un conocimiento de la materia a través del texto planteado, (2) comprender el contenido del texto, (3) analizar ese conocimiento aprendido, (4) aplicarlo y, por último, (5) evaluar el conocimiento del texto.

Resulta incuestionable que el comentario de texto es una actividad ambiciosa, con un grado de complejidad evidente y costosa en el tiempo. Además, recurre a conocimientos previos, no siempre disponibles para el alumno. Por lo tanto, en un momento donde el acelerado ritmo de vida exige al alumno apresuramiento al realizar sus tareas, donde es fácil ceder ante la tentación de la gratificación inmediata, el comentario de texto resulta la antítesis de esta inmediatez. En efecto, precisa reflexión sosegada, pensamiento especulativo y capacidad analítica. A la larga, empero, imprime carácter, pues enseña a ordenar de manera lógica, sistemática y creativa las reflexiones del alumno sobre una pregunta, una cuestión o una interpelación, con independencia de la materia concreta. Es una vacuna contra el relativismo subjetivista que afirma que todas las opiniones son válidas, pues afirma el peso específico del conocimiento para formar 
un criterio. Es decir, comentar un texto implica pensar por escrito.

\section{Leer, comprender y argumentar: didáctica del comentario de texto}

Cuando el alumno se enfrenta a un texto no solo asimila una suerte de datos aparentemente inconexos y eruditos. Si el profesor ha seleccionado un texto adecuado para el horizonte cognitivo y el desarroIlo de la madurez del estudiante, es posible abordar un proceso doble. Por una parte, desentrañar la división entre forma y contenido, discriminar entre la expresión y el objeto expresado, descubrir los recursos estilísticos y los conceptos susceptibles de ser estudiados. Por otra, facilitar que el alumno adquiera la competencia de procesar e interpretar informaciones pertinentes y relevantes frente a aquellas que son solo accesorias, es decir, una suerte de ruido de fondo. Este aspecto posibilita que el alumno descubra otras imágenes del mundo, en suma, otros marcos de referencia de quienes nos precedieron.

En consecuencia, el comentario de texto potencia aptitudes de lectura y escritura, de reflexión especulativa y de análisis de la información. Este diálogo intelectual escrito con los textos precisa de capacidad interpretativa y argumentativa. Confiere la oportunidad al lector de asociar ideas, opinar y tomar decisiones sobre los conceptos y las ideas más relevantes de cada texto. Es un paso cognitivo superior al de la comprensión, porque construye nuevos sentidos por medio de la interpretación y argumentación del texto, de la capacidad crítica, la interdisciplinariedad y la transversalidad del conocimiento. Además, la intertextualidad facilita que el alumno aprenda - a través de las distintas reglas de cada ecosistema textual - la multiplicidad de marcos hermenéuticos de las Ciencias Sociales y Humanas, puesto que si es capaz de sortear acertadamente las dificultades del texto histórico puede aproximarse con mayores garantías a un texto literario o filosófico.

En última instancia, el comentario de texto aspira a producir un cambio epistemológico en el estudiante. Es preciso

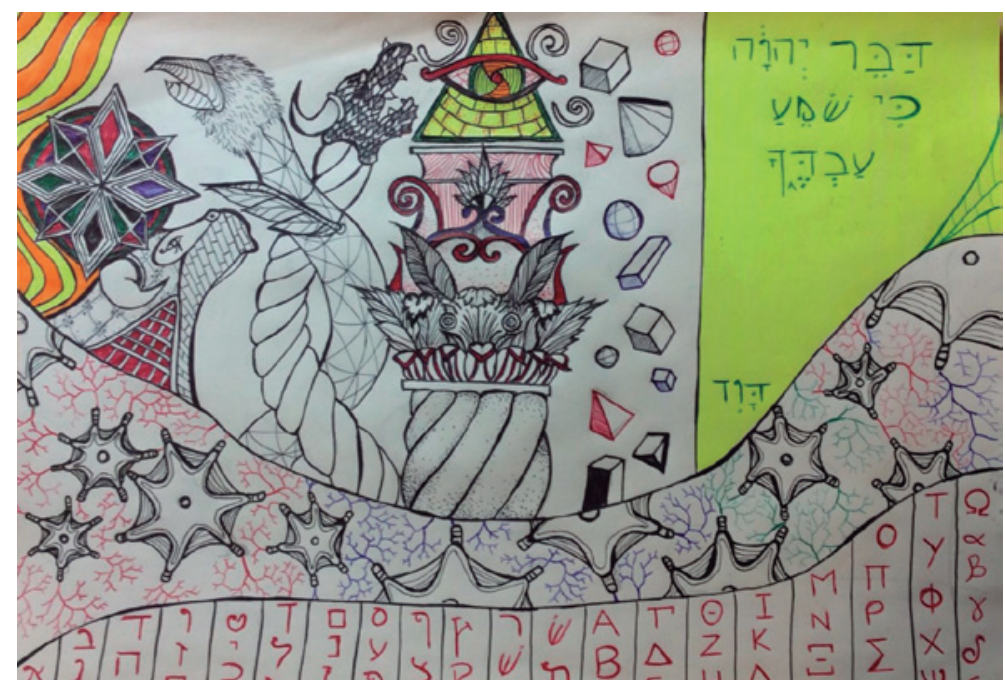

superar la obsoleta consideración del comentario de texto como mera glosa, disertación ordenada y ejercicio de erudición filológica. El docente es el guía en un proceso que permite al alumno profundizar en las construcciones discursivas propuestas en el texto, en las ideas principales y las secundarias, en los procesos argumentativos y persuasivos fundamentales. Por este motivo, artículos de opinión, fragmentos de documentos históricos, obras literarias y filosóficas, todos ellos son idóneos por su brevedad, su variada temática y la riqueza de matices que pueden incentivar al alumno a que forme parte de esta hermenéutica textual.

En definitiva, leer, comprender y argumentar son competencias esenciales que facilitan el acceso al conocimiento y hacen más libre al alumno. Para conformar la capacidad de discriminar la pertinencia y relevancia de las ideas expresadas, contextualizar el texto y manifestar una valoración crítica personal es preciso un enfoque didáctico nítido por parte del docente. Por ese motivo propondré a continuación algunas líneas orientativas de aplicación práctica.

\section{De la teoría a la práctica}

El texto es un paraje con sus propias reglas, sus senderos y sus atajos. También con falsos derroteros y caminos inciertos. Por eso, cada texto tiene unas
Luis David Ocón Ruiz (alumno del Instituto Teológico Lucense). Proceso del comentario de texto, desde la asimilación de los signos lingüísticos pasando por un itinerario cognitivo y hermenéutico hasta alcanzar las ideas abstractas, imaginativas y fantásticas 
Existen numerosos esquemas para elaborar comentarios de texto, como por ejemplo los célebres y especializados modelos de la Universidad de 0xford o del Baccalauréat francés. No obstante, los equipos docentes pueden partir del siguiente esquema:

1. Lectura atenta del texto propuesto: de una primera lectura el alumno puede extraer una idea del contenido general mientras que tras una segunda aproximación —el famoso subrayado — es posible detectar los términos fundamentales, problemas esenciales y la estructura argumentativa fundamental.

2. Análisis del texto: en primer lugar (a), el alumno debe realizar un análisis objetivo — del contenido — en busca de las ideas principales y secundarias, mientras que, en segundo lugar (b), atiende al análisis formal — sintáctico, estilístico y semántico-.

3. Análisis del contexto: en este apartado el alumno debe aludir al autor, a su contexto, es decir, al periodo, estilo o momento histórico 0 artístico concretos.

4. Interpretación del texto: el alumno debe enunciar las preguntas o problemas que plantea el texto, para descubrir la intención del autor, la relevancia del fragmento comentado, su aportación y repercusión posteriores.

5. Comentario crítico e información extratextual: analizar el contenido de las ideas centrales y secundarias, de los presupuestos que las sustentan y de sus contradicciones e inconsistencias.

6. Valoración crítica personal: esta faceta del comentario es la más subjetiva y el docente debe animar al alumno a que elabore unas conclusiones concisas, argumentadas y fundadas.
Aunque cada materia presenta sus especificidades metodológicas, la interdisciplinariedad del comentario de texto permite abordar un esquema o mapa organizativo transversal que siga los siguientes pasos: (i) análisis del texto, (ii) interpretación y (iii) crítica. A continuación, expondré con mayor detalle este esquema.

En primer lugar (i), el análisis del texto implica un estudio objetivo del contenido - de sus ideas centrales y secundariasy un examen formal, sintáctico, estilístico y semántico. Las famosas técnicas de subrayado ayudan a revelar nexos sintácticos y concatenaciones argumentales. Por otra parte, también resulta preceptivo analizar contextualmente el fragmento sugerido. A tal fin se debe atender al autor (o autores), a la obra a la que pertenece el texto y a su relevancia dentro de la obra del autor. El análisis, en su conjunto, permite ubicar el texto, destacar su tesis principal, jerarquizar las ideas y contextualizarlas en el ámbito de un determinado autor o de un momento histórico relevante.

A continuación (ii), el texto debe ser interpretado, esto es, aludir a las preguntas planteadas o respondidas por el texto, descubrir la intención del autor y ponderar la relevancia de este fragmento para el ámbito académico correspondiente. De esta manera es posible aprehender los elementos implícitos, las lagunas del texto, las repercusiones posteriores o las rupturas que plantea con el pasado. Corresponde a un proceso hermenéutico en el que el alumno se aventura a descifrar las ramificaciones del texto.

Finalmente (iii), el alumno critica el contenido - las ideas planteadas y sus consecuencias- así como las incongruencias, ambigüedades o falacias. Además, debe realizar una valoración personal, una interpretación para una futura práctica profesional o para su maduración cognitiva. De este modo, parece que el alumno relativiza el texto pero va un paso más allá. Lo hace suyo y lo integra en su horizonte vital, en sus perspectivas de crecimiento y en sus estructuras 
antropológicas. Solo así el comentario de texto resulta fecundo y no queda reducido a un ejercicio de erudición filológica.

\section{Conclusiones}

En definitiva, el comentario de texto es un diálogo del autor con el lector, en este caso un alumno. Comprender al autor implica entender su universo conceptual, su contexto, sus intenciones y la relevancia en un diálogo intergeneracional. Por este motivo, equivale a descubrir un horizonte hermenéutico, a comprender mejor el mundo que le rodea y los senderos por los que se bifurca. Además, por medio de esta actividad reflexiva, el alumno adquiere el hábito de dialogar, de cuestionar a los autores de los textos estudiados. De esta manera, el estudiante se encamina hacia la madurez crítica y la capacidad de discriminar la información relevante del mero ruido.

En un momento en el que se ponderan sin parangón las nuevas metodologías, realizar una apología del comentario del texto no supone una revolución pedagógica. Por el contrario, equivale a restaurar la tradición pedagógica - acaso una de sus mejores partes - por medio de un instrumento esencial para la enseñanza y el aprendizaje de la Historia, de la Lengua, de la Literatura, de la Filosofía, esto es, de todas las disciplinas emparentadas con las Ciencias Sociales y Humanas. Parece que en un momento de penuria teórica y de vaciamiento de estos enclaves académicos, recuperar la creatividad, la expresividad y la capacidad analítica de los

\section{HEMOS HABLADO DE}

\section{Comprensión lectora; pensamiento crítico; escritura (redacción); pensamiento creativo.}

Este artículo fue solicitado por PADRES Y MAESTROS en marzo de 2020, revisado y aceptado en junio de 2020.

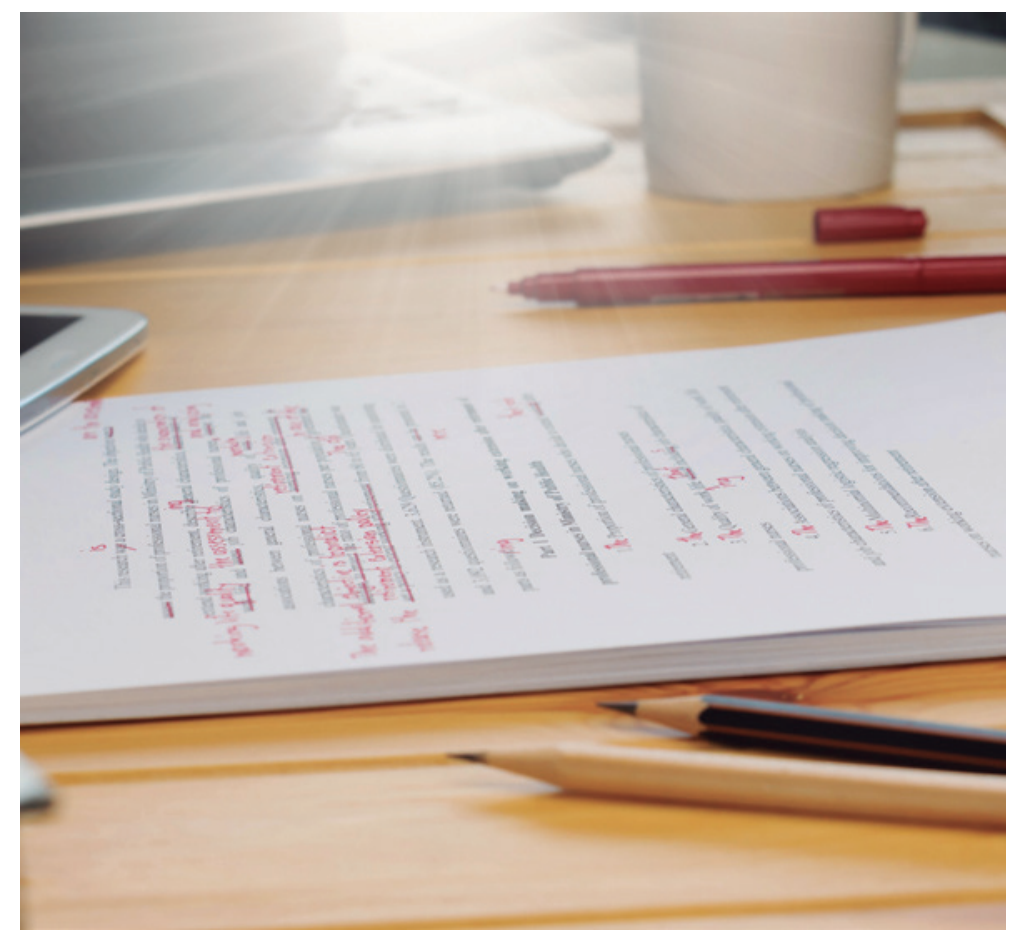

\section{Comentar un texto es una invitación a protagonizar las aventuras previas de la historia \\ y la cultura, a interrogarse sobre el fundamento de las sociedades}

estudiantes es un objetivo idealista, una ensoñación. Por este motivo, el comentario de texto está llamado a recuperar un papel central para quienes aspiramos a que los alumnos sean capaces de leer, comprender y argumentar •

\section{DD. DARA SABER MÂS}

Caro Valverde, M. T. y González García, M. (2018). Didáctica en la argumentación en el comentario de textos. Madrid: Editorial Síntesis.

Jiménez Calderón, F., y López Martín, I. (eds.) (2017). Metodología para el trabajo con géneros discursivos académicos. Cáceres: Universidad de Extremadura.

Núñez Cortés, J. A. (coord.) (2015). Escritura académica. De la teoría a la práctica. Madrid: Pirámide. 